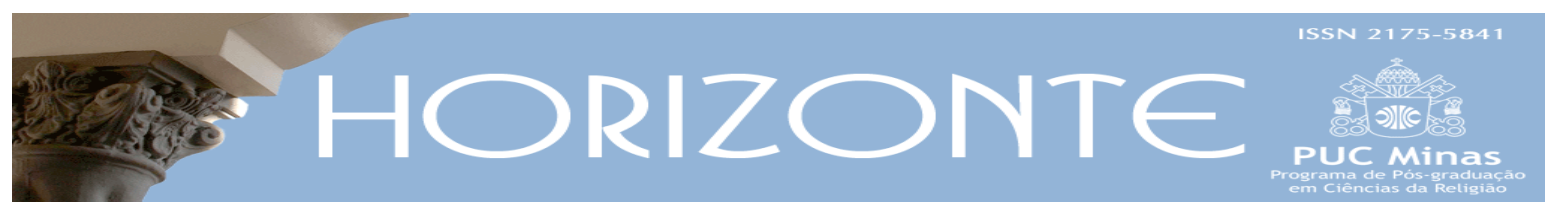

Dossiê: Fundamentalismos e Democracia - Artigo Original (a) (1)

\title{
Gianni Vattimo e Jean-Luc Nancy: o fundamentalismo democrático
}

\author{
Gianni Vattimo and Jean-Luc Nancy: \\ the democratic fundamentalism
}

\author{
Julio Paulo Tavares Zabatiero* \\ Jonathan Michelson de Menezes**
}

\begin{abstract}
Resumo
Este artigo tem como tema a democracia enquanto fundamentalismo, ou o fundamentalismo democrático. Seu objetivo principal é o reconhecimento de que o pensamento sobre a democracia pode ser, ele mesmo, fundamentalista, de modo que não só os fundamentalismos religiosos são uma ameaça à democracia contemporânea. Trata-se de uma interpretação de textos de dois filósofos contemporâneos que não costumam dialogar entre si, o italiano Gianni Vattimo e o francês Jean-Luc Nancy. A tese do ensaio é a afirmação do pensamento democrático enquanto uma forma de fundamentalismo, na medida em que ele cumpre certas condições estabelecidas pelos dois pensadores analisados. Estas condições são, na linguagem dos filósofos citados, o enquadramento da democracia sob o pensamento forte, ou a sua subsunção a um modo metafísico de pensar, de modo que se torna incapaz de autocrítica e de sua necessária reinvenção. Assim, espera-se contribuir para a construção de uma visão autocrítica da democracia mediante o diálogo com aspectos do pensamento pouco conhecidos de importantes filósofos da atualidade e também mediante o diálogo entre filosofia e teologia enquanto modos emancipatórios de saber.
\end{abstract}

Palavras-chave: Jean-Luc Nancy. Gianni Vattimo. Democracia. Fundamentalismo. Teológico-político.

\begin{abstract}
This article has as its theme the democracy as fundamentalism, or the democratic fundamentalism. Its main objective is the recognition that the thinking about democracy can itself be fundamentalist, implying that not only religious fundamentalisms are a threat to contemporary democracy. Its method and object are the interpretation of texts by two contemporary philosophers who do not usually talk to each other, the Italian Gianni Vattimo and the French Jean-Luc Nancy. The essay's thesis is the affirmation of democratic thinking as a form of fundamentalism, insofar as it fulfills certain conditions established by the two thinkers analyzed. These conditions are, in the language of the aforementioned philosophers, the framing of democracy under the so-called strong thought, or its subsumption to a metaphysical way of thought, so that it becomes incapable of self-criticism and its necessary reinvention. Thus, it is expected to contribute to the construction of a self-critical vision of democracy through dialogue with aspects of thought little known of important philosophers and also through the dialogue between philosophy and theology as emancipatory ways of knowing.
\end{abstract}

Keywords: Jean-Luc Nancy. Gianni Vattimo. Democracy. Fundamentalism. Theological-political.

Artigo submetido em 30 de julho de 2020 e aprovado em 18 de dezembro de 2020.

* Doutor em Teologia pelas Faculdade EST. Professor da Faculdade Teológica Sul Americana. País de origem: Brasil. E-mail: jzabatiero@uol.com.br

** Doutor em História pela Unesp. Professor da Faculdade Teológica Sul Americana. País de origem: Brasil. E-mail: jonathan@ftsa.edu.br 


\section{Introdução}

Enfrentamos, no Brasil contemporâneo, a mais perigosa crise política após a redemocratização que se seguiu ao golpe militar de 1964. A eleição do presidente Bolsonaro trouxe à luz e ao exercício do poder estatal uma forma de pensar e agir de cunho fascista, totalitário, controlada de modo tenso pelo confronto entre os poderes, bem como pelo (ainda) predomínio de uma opinião pública pródemocrática. O que está em jogo, para muitos analistas, não é só o exercício de um mandato presidencial, mas a própria saúde da democracia - ameaçada por esse modo fascista de pensar a coisa pública e de agir social e politicamente. O quadro da crise é completado pela presença da religião cristã como um fator legitimador da eleição e da atuação de nosso atual presidente - que tem se cercado de quadros militares, por um lado, e 'terrivelmente' evangélicos, por outro - que busca construir uma legitimidade para a qual o resultado eleitoral é insuficiente.

Diante do complexo quadro que se apresenta, complicado ainda mais pela presença de uma crise de saúde pública sem precedentes nos últimos cento e cincoenta anos, não são poucas as análises, com valor diversificado, da presença e do papel da religião e da teologia no espaço público e, mais especificamente, na esfera estatal. Não é à toa que a discussão sobre o fundamentalismo voltou à superfície e tem um papel importante na compreensão da realidade política brasileira atual. Uma forma de viver a fé cristã, de cunho fundamentalista, que flerta constantemente com um estilo fascista de viver e de fazer política, encontrou um amplo espaço de atuação na esfera estatal e, ao mesmo tempo, tem ocupado amplos espaços na mídia apresentando suas justificativas teológicas para o projeto conservador de direita que apoiam e representam.

O perigo do fundamentalismo religioso tem se tornado claramente reconhecido, embora a sua crítica teológica ainda não tenha sido feita de modo contundente e reflexivo. Todavia, entendemos que além da crítica ao fundamentalismo religioso, enquanto ameaça à democracia, é indispensável uma autocrítica da democracia que parta do reconhecimento de que o fundamentalismo 
não é apenas um inimigo ‘externo’ à razão democrática, mas, ao contrário, faz parte do próprio modo democrático de pensar desde suas origens modernas. Assim, neste artigo trazemos ao diálogo dois pensadores que não costumam citar um ao outro, nem costumam ser estudados como 'parceiros' de pensamento filosófico. Propomos, sob este prisma, um diálogo inusitado.

Os dois filósofos que aqui discutimos, porém, possuem muito mais em comum do que costumeiramente se reconhece. Ambos são da mesma geração de pensadores europeus que experimentaram a crise civilizatória da Europa que culminou na constituição da União Europeia e de todos os modos de pensar e viver politicamente dela consequentes. Ambos podem ser descritos como filósofos pósmetafísicos ou pós-modernos, leitores assíduos e críticos de Nietzsche e Heidegger, fundadores, cada um a seu modo, de novas tendências epistemológicas e ontológicas na filosofia contemporânea. Ambos defendem, cada um a seu próprio estilo, a ideia do comunismo como ‘solução' para a crise da democracia europeia contemporânea. Um deles é o italiano Gianni Vattimo, conhecido como fundador do pensamento fraco, proponente de uma nova hermenêutica que pode ser nomeada, como se faz no título de um de seus livros, de comunismo hermenêutico. O segundo, Jean-Luc Nancy, parceiro e co-autor de Philippe Lacoue-Labarthe, ambos, por sua vez, importantes interlocutores de Jacques Derrida. Nancy pode ser descrito como proponente de uma nova ontologia, a do ser-com, da essência humana como a relação, como o estar-presente-no-mundo-com, e não apenas como um ser-aí.

Apresentaremos, levando em conta os diferentes estilos dos dois autores, e as diferentes abordagens dos mesmos ao tema da democracia, uma síntese de sua visão crítica da política contemporânea. A seção sobre Gianni Vattimo é menos marcada pela voz do filósofo, enquanto a sobre Nancy é construída de modo a privilegiar a presença da voz do próprio filósofo, mediante o uso de citações mais amplas de sua obra. A diferença se justifica, primariamente, pelo modo como ambos abordam o tema da democracia enquanto fundamentalismo. Enquanto Vattimo aborda mais diagonalmente a questão, Nancy tem dedicado uma série de 
textos ao tema a partir de 1999 - textos não tão conhecidos entre nós, especialmente em círculos teológicos, de modo que as citações se justificam como modo de tornar conhecido de modo mais amplo o pensamento deste autor.

Nossa tese é que ambos nos oferecem subsídios suficientes para fazer uma crítica da democracia 'a partir de dentro', afirmando que o fundamentalismo perigoso para a democracia não é apenas o religioso, mas também o próprio pensamento e a própria prática da democracia na atualidade. Se este diagnóstico estiver correto, podemos ver nos dois filósofos parceiros para a construção de uma crítica teológica da democracia que seja feita enquanto parte da vivência democrática, não mais como um exemplo de imposição do 'teológico-político' à esfera autônoma da política. Derrotar o fundamentalismo enquanto modo de pensar e viver a democracia é, na visão de ambos, com a qual concordamos, um imperativo urgente e necessário de nosso tempo. A descrição da crítica de cada um deles à democracia, apresentando as condições que tornam legítimo falar em fundamentalismo democrático, ou ‘democracia enquanto fundamentalismo’ é aqui, então, apresentada como um convite ao diálogo.

\section{Gianni Vattimo: o "adeus à verdade" na era da democracia}

No pensamento filosófico de Gianni Vattimo, é possível começar destacando sua predileção pelos filósofos alemães, em especial Nietzsche e Heidegger, que o suportam no postulado de uma filosofia pós-metafísica e niilista; a primeira, parte do anúncio do "fim da metafísica” e, como corolário, da descrença na possibilidade de uma descrição objetiva da realidade em si, crendo apenas a existência de leituras várias e a produção de um conhecimento participativo, envolvido e não neutro, que resiste em apelar para um fundamento universal ou aos "grandes relatos"; já o niilismo, para Vattimo (2004, p. 132), "é a perda da crença em uma verdade objetiva em favor de uma perspectiva que concebe a verdade como efeito de poder", isto é, como efeito de acordos comunitários localizados. Esta forma de contrapoder intelectual anuncia, também, uma espécie de elogio à fraqueza como condição para a pluralidade e o diálogo. 
Vattimo expressa isso em um de seus mais conhecidos conceitos, que ele chama de "pensamento fraco" (pensiero debole). "Fraco", na concepção de Vattimo (2004, p. 30), “é o reconhecimento nietzschiano de que não podemos evitar que se fale em termos metafóricos, isto é, em termos que não são objetivos nem descritivos, que não espelham o estado de coisas”. Embora tenha trabalhado esta noção mais especificamente na obra que leva o mesmo nome (Il pensiero debole, 1983), ela irá reaparecer de forma expressa e diluída ao longo de toda a sua obra posterior. Em sua autobiografia “escrita a quatro mãos", Vattimo, porém, esclarece que seu anúncio de um pensamento capaz de se articular à "meia-luz" não deveria ser interpretado como uma espécie de timidez ou desvanecimento, mas como um projeto emancipatório do humano. Ou seja, "paradoxalmente, é na sociedade de massas que se faz necessário sermos super-homens, porque devemos nos tornar intérpretes autônomos" (VATTIMO, 2018, p. 103). Enquanto estivermos aqui, acredita ele, devemos inventar nossa própria voz, do contrário não estaremos realmente aqui, mas somos engolidos, desaparecemos. De tal maneira que a filosofia do pensamento fraco é "uma teoria forte, uma proposta filosófica forte", porque fundada numa ética não agressiva - e, convenhamos, é necessária muita força no atual estado de coisas da democracia ocidental para não sucumbir ao caminho fácil da violência reacionária.

Em Adeus à verdade (2016), Vattimo retoma a ideia de que a pretensão à verdade é funesta numa era pós-metafísica (ou pós-moderna), em que presumidamente se reconhece que não temos acesso à verdade pois não vemos o todo, a essência, a coisa em si. Percebe-se também ali o interesse em ver como essa questão adentra o campo da política, propondo, assim, uma fenomenologia (ou ontologia) da atualidade, tendo como foco particular a democracia, que, segundo ele, é o signo prático do antifundacionalismo por ele recomendado no que ele chama de "fim da filosofia", isto é, "da filosofia entendida como função soberana dos sábios no governo da polis". É preciso, portanto, repensar a tarefa do pensamento nesse contexto em que "os filósofos não creem mais ter um acesso privilegiado às ideias e às essências, que os colocaria em condições de governar ou dar normas ao soberano" (VATTIMO, 2016, p. 33, 35). 
É o que ele se propõe a fazer no primeiro capítulo do referido livro, onde explora a relação entre a filosofia e a política contemporânea preconizando uma “política sem verdade". Para ele, o mito da verdade objetiva, isto é, da verdade como correspondência entre uma representação da realidade e a realidade mesma, acaba sendo não só inimigo de um saber científico possível, como também da própria democracia, não apenas como conceito, mas, sobretudo, como prática. Assim, o "adeus à verdade" como correspondência é o início e a base da democracia, pois onde há democracia não pode haver uma classe de detentores da "verdade verdadeira", que exerçam o poder de forma direta ou indireta (VATTIMO, 2016, p. 33). Esse adeus ocorre, assim, a partir do reconhecimento de que a verdade não se encontra "lá fora", mas é fruto da interpretação e construção, individual e comunitária, pelo consenso e o respeito à liberdade de cada um. Logo, o que temos não é a verdade, mas são as verdades particulares, isto é, que são não universalmente, mas localmente válidas e sempre passíveis de revisão. Na medida em que se reconhece isso, afirma ele, "muitos autoritarismos são desmascarados pelo que são, isto é, pretensões de impor-nos comportamentos com que não concordamos em nome de uma lei natural qualquer, uma essência humana, uma tradição intocável, uma revelação divina etc.” (VATTIMO, 2016, p. 24-25).

No fim da verdade está o início da democracia (VATTIMO; ZABALA, 2012, p. 38). Vimos que essa é uma ideia central para Vattimo. Entretanto, pode-se dizer que dentro da própria democracia podemos encontrar lógicas que contrariam esse princípio e levam, de novo, ao domínio da verdade e ao desejo de dominação. Vattimo (2012, p. 12) sugere que a democracia está passando por uma crise, que ele identifica como uma "crise de falta de urgência", ocasionada pela "neutralização" (o comodismo cínico dos "vencedores" da democracia, que não querem que as coisas mudem porque elas vão bem para eles, a despeito de por vezes irem muito mal para os "vencidos"), ausência de mudanças e de transformações no presente estado de coisas. Aqui surge o conceito, empregado por Vattimo e Zabala (2012), de "democracia enquadrada", isto é, a democracia que, no viés ideológico e de governança, se apresenta como "a única legítima no exercício de estabelecer com precisão seus limites (o que não é democrático, o que se encontra fora da 
democracia, o que não pode ser discutido, etc.)”, e que não responde aos apelos de representação popular ou de redistribuição social (MÉNDEZ, 2014, p. 175). Em outras palavras, uma democracia para alguns, o que, convenhamos, não é realmente uma democracia, que pressupõe participação popular e, na perspectiva pós-metafísica, uma conversação aberta e sem previsão de término (sobretudo, no sentido vertical de quem deliberadamente "encerra" ou coíbe certos tipos de conversa).

Numa democracia como esta as urgências são, por assim dizer, “impostas”, seja pelo viés liberal, que considera o fator econômico e o poder do indivíduo como sendo os únicos essenciais (VATTIMO; ZABALA, 2012, p. 76), ou pelo viés “comunitário" ou dos direitos, que dão a valores como o de "igualdade" um status quase metafísico (VATTIMO, 1997, p. 6). Todos aqueles que não se adequam ao "ordenamento dos fatos, normas e instituições" de acordo com tal o qual perspectiva, deve ser alijado ou mesmo eliminado. Isso é uma tendência forte, por exemplo, em casos de emparelhamento ideológico do estado, em que a "máquina estatal" é utilizada (sob o signo da democracia) para fins puramente ideológicos e que, como tais, tendem a ignorar o chamado "bem-comum". Isso dá sinal verde, por exemplo, para bizarrices antidemocráticas que temos visto no Brasil atual. Algo que testemunhamos recentemente: um famoso "youtuber", correligionário e apoiador do atual chefe do executivo, vociferando em um vídeo para que seu presidente cumprisse uma de suas capitais promessas de campanha que foi a de “acabar com o socialismo no Brasil”. Isso nos leva a imaginar como exatamente ele faria isso sem o uso totalmente deslegitimado da violência e da exclusão.

Esse é, obviamente, apenas um dentre os inúmeros exemplos que podem identificar o que os autores chamam de "democracia enquadrada", ou seja, a democracia que descamba para o que Vattimo chama de "violência da verdade", que pode inclusive aparecer sob o disfarce de uma agenda moral, que, por sua vez, tenta neutralizar todas as outras opções que contrariem aquela que reclama para si o status de "absoluta”. Desse modo, afirmam os autores, "todo aquele que dentro da democracia enquadrada se negue a se submeter à verdade, ao diálogo ou à 
estrutura previsível de causas e efeitos constitui não apenas uma 'alteração da história', como também um potencial perigo, e como tal haverá de ser identificado" (VATTIMO; ZABALA, 2012, p. 56). Daí a necessidade, a que Vattimo chama a atenção em vários de seus escritos, que se priorize ações visando o que ele chama de "redução da violência" provocada por aspirações de cunho metafísico, e que demos "adeus" à ilusão de correspondência - dos valores, ideologia e crenças de alguém ou de grupos - com a verdade. O que pressupõe, como ele vem defendendo há certo tempo, a "dissolução de todas as estruturas estáveis", que deve resultar:

\footnotetext{
Na secularização das tradições religiosas e da autoridade política; Na dissolução de toda base de certeza em torno do sujeito;

$\mathrm{Na}$ fragmentação de toda racionalidade central produzida pela multiplicação de paradigmas científicos que resistem a quaisquer esforços unificadores;

E na pluralização de universos culturais contra a ideia de um caminho singular e unificado para a história humana (VATTIMO, 1997, p. 4).
}

Esta versão de uma liberdade democrática - contra o que ele chama de "democracia enquadrada" - pode nos conduzir, como corolário, a um impasse ético, que Vattimo resume na seguinte pergunta: como justificar, do ponto de vista hermenêutico, o sincero escândalo que nos provocam tantos políticos que mentem? Ou seja, no "adeus à verdade", como reconhecer e denunciar a mentira nociva ao bem individual ou comum? Coadunar-se-á com a descarada mentira? Ou, indo adiante, sem o parâmetro da verdade, como é possível se definir e diferenciar coisas tais como "mentira" e "bem comum"? Se a verdade absoluta é "mais um perigo que um valor", que valores ainda podem ser defendidos que não resultem no mesmo perigo ora rechaçado - o de absolutizar aquilo que é apenas particular? A resposta de Vattimo é uma solução aberta e provisória ao problema: se é passível que tal conflito não pode ser vencido pela pretensão de se chegar à verdade das coisas, uma vez que o resultado sempre será diferente da verdade mesma, resulta que não mais se busque a verdade universal, mas a verdade comunitariamente válida ao grupo numa situação histórica dada. No adeus à verdade suspende-se a pretensão a uma validade universal de pressupostos, e se dá boas-vindas a "verdades particulares" com validade relativa e temporária. Assim, não se trata de um total abandono da tarefa de distinguir práticas ou discursos que sejam 
verdadeiros ou falsos, mas de reconhecer que "a diferença entre verdadeiro e falso é sempre uma diferença que surge de interpretações mais ou menos aceitáveis e compartilhadas", como produto não do autoritarismo da visão de uns sobre outros, mas de consensos solidariamente possíveis. Não que o papel do diálogo seja, necessariamente, o de produzir consenso, nem que o do intelectual não possa ser o de persuadir seus pares de sua posição. A diferença, para Vattimo, está na palavra interpretação, de modo que: "A filosofia não é expressão da época, é uma interpretação que, claro, se esforça por ser persuasiva, mas que reconhece sua própria contingência, liberdade, riscosidade” (VATTIMO, 2016, p. 55).

A filosofia que emerge, então, dessa reafirmação do pluralismo cultural pósmoderno, é uma filosofia carente de princípios últimos ou, por assim dizer, pósfundacionalista. Mas, se ela é niilista, débil de fundamentos e de uma origem, como pode falar racionalmente e/ou não descambar para um irracionalismo puro e simples do tipo "vale-tudo"? Na perspectiva de nosso autor, ela o faz a partir de “eleições responsáveis” ou pontos de partida explícitos (não neutros, nem universalizantes), que surgem de “imperativos" ditados não pelo olho de Deus subjacente a toda moral, mas pelo contexto e suas situações específicas. Vattimo parece propor, assim, a troca de uma ética universal (com imperativos categóricos) por uma ética situacional (com imperativos contextuais, forjados a partir de uma pertença comunitária). Isto ele chama de ética da finitude: "aquela que busca permanecer fiel à descoberta da situação sempre insuperavelmente finita da própria proveniência sem esquecer das implicações pluralísticas dessa descoberta” (VATTIMO, 2016, p. 99).

Se se mantém o valor da procedência, isto significa que a herança cultural ou a tradição não tem que ser desprezada. O que muda é o critério elegido para o acordo sobre o que "vale" e o que "não vale" da herança, que é o do diálogo ou encontro entre éticas finitas que, reconhecendo-se como tais, não cederão facilmente à tentação de imposição da verdade de uma sobre a(s) outra(s). Ou seja, numa ética da finitude o outro não mais se vê coagido ao silêncio em nome de princípios, mas respeitado em seu direito de fala/vida. "O respeito do outro", como 
define Vattimo, "é sobretudo o reconhecimento da finitude que caracteriza a ambos e que exclui qualquer superação definitiva da opacidade que cada qual carrega consigo" (VATTIMO, 2016, p. 102). Desta feita, uma ética da finitude não abdica da racionalidade, mas reconhece a precariedade e provisoriedade dos saberes e posições deles provenientes. Isto ajuda a manter longe a ilusão de se ver do lado da "moral", da verdade e da pretensão de impô-las ao resto do mundo, bem como de transformar a democracia em um tipo aparentemente sofisticado de fundamentalismo.

\section{Jean-Luc Nancy: a democracia enquanto ausência de significado}

Enquanto Vattimo nos permite pensar a democracia enquanto fundamentalismo a partir da relação com a verdade - tanto em sentido epistêmico, quanto em sentido ético, Nancy nos possibilita pensar a democracia enquanto fundamentalismo a partir da relação com o significado - tanto em sentido semântico, quanto em sentido ontológico - que é constitutivo do ser-com - o ontos humano. A democracia se torna fundamentalista quando perdemos a capacidade de questionar o seu significado, quando ela se torna tão verdadeira, tão unicamente verdadeira que perde toda a possibilidade de significar. Nas palavras do próprio Jean-Luc Nancy:

A democracia se tornou um caso exemplar de perda do poder de significar: representando tanto a virtude política suprema quanto o único meio de realizar o bem-comum, ela cresceu tanto que não foi mais capaz de gerar qualquer problemática ou de servir a qualquer propósito heurístico. Tudo o que se passa na atualidade é o debate marginal a respeito dos vários sistemas e sensibilidades democráticas. Em suma, democracia significa tudo - política, ética, lei, civilização - e nada. (NANCY, 2011, p. 58). ${ }^{1}$

\footnotetext{
${ }^{1}$ Um dos sintomas mais evidentes dessa perda de capacidade significante é a crença na singularidade da democracia, no caráter único da democracia enquanto regime político emancipatório e humanizador - que apenas revela a fragilidade da democracia agora tão reconhecida em todo o Ocidente: "na medida em que uma certa convicção democrática passa a ser afirmada mais ou menos em todo lugar, começamos a nos perguntar mais e mais acerca da fragilidade da democracia. Quando se toma por certo em cada discurso que 'democracia' é o único tipo de regime político aceitável para uma humanidade que amadureceu, que se emancipou e que não tem outro fim além de si mesma, então a própria ideia de democracia perde o seu brilho, murcha e nos deixa perplexos" (NANCY, 2010, p. 37).
} 
De fato, para o pensador francês, a democracia jamais conseguiu se libertar de seu fundamento religioso e o pensamento sobre a democracia jamais deixou de ser um pensamento teológico-político (nos escritos de Nancy sobre este tema, a expressão é usada a partir dos textos de Carl Schmitt a quem, é claro, Nancy se opõe radicalmente), ou seja, um pensamento que em sua ânsia totalizante, de a tudo significar, reduz-se a um nada de sentido. Redução que já está na base do pensamento democrático moderno, em seu discurso de origem.

O mito de origem da democracia moderna é figurado como o contrário da Cristandade: (a) radical separação entre o Estado e a Igreja como base do processo de secularização, com a consequente afirmação da autonomia em relação ao divino; (b) uma nova racionalidade, suprema e autônoma em relação à revelação e ao caráter dogmático da teologia; (c) um novo projeto emancipatório, civilizatório, sem Deus, sem religião. Nancy, porém, considera que o mito de origem oculta o fato de que a democracia jamais rompeu com o teológico-político. Por isso, Nancy pergunta, "esta palavra, em última instância, designa a reconfiguração do teológico-político mediante uma metamorfose transcendente-negativa ou positivaimanente, ou ela designa uma genuína ruptura com o teológico-político?” (NANCY, 2010, p. 40, itálicos dele).

E a resposta não pode ser outra: ela (ainda) não designa uma genuína ruptura com o teológico-político. De modo análogo ao texto fragmentário de Benjamin, devemos falar de democracia enquanto religião. Uma religião que, submetida ao teológico-político, encena a emancipação da humanidade apenas para refigurar a sua escravidão, na medida em que ela, democracia, se torna o fundamento da vida em comum, confundindo a vida com o político, transformando o político em uma esfera totalizante, substituindo Deus e reconfigurando sua divindade em termos ilusoriamente imanentes:

De outro modo, assemelhando-se à 'razão' kantiana, democracia designa as Ideias de Humanidade e/ou Mundo, na medida em que elas postulam sua própria capacidade de serem sujeitos de transcendência ilimitada e de completa autonomia, a despeito de terem renunciado à sua crença em outros mundos além deste e de terem compreendido sua própria imanência e individualidade como sacrossantas. (NANCY, 2010, p. 59). 
Desta forma, como a segunda pessoa da Trindade, em seu caráter híbrido divino-humano, a democracia se concretiza enquanto apostolicidade, assumindo e praticando fielmente a sua missão civilizadora supostamente emancipatória:

a democracia promove e promete a liberdade do ser humano em sua totalidade dentro da equidade de todos os seres humanos. Neste sentido, a democracia moderna engaja absoluta e ontologicamente o ser humano e não apenas o 'cidadão'. Ou, de outro modo, ela tende a fundir os dois. Em qualquer caso, a democracia moderna corresponde a muito mais do que apenas a uma outra mutação política. Estamos falando, aqui, de uma mutação da cultura e da civilização, tão profunda que ela alcança as mesmas proporções antropológicas das mutações tecnológica e econômica que vieram juntamente com ela. É por isso que o contrato de Rousseau não institui apenas um corpo político, ele produz a própria humanidade, a humanidade do ser humano. (NANCY, 2010, p. 59-60).

Não é difícil reconhecer nestas duas últimas citações os contornos conceituais do dogma doutrinário-teológico da Igreja: a promessa eficaz da liberdade plena do ser humano, cuja identidade como 'pecador' anula todas as diferenças e possibilita uma universalidade apropriadamente salvífica (conforme BADIOU, 2009), constituindo uma nova identidade - filho(a) de Deus - que subsume todas as dimensões da vida humana; o caráter escatológico-apocalíptico da salvação, que inaugura uma nova era da humanidade, tão radicalmente totalizante que se pode chamar, como o faz Paulo, de novo humano, recriado e refigurado, no Messias, como imagem e semelhança de Deus (especialmente em suas cartas aos Romanos, Efésios e Colossenses). Não se trata, portanto, apenas de uma secularização dos conceitos teológicos, mas de uma transfiguração do divino, mediante a qual a democracia se encarna no mundo como a segunda pessoa da Trindade o fizera de acordo com a mensagem cristã.

Não só foi incapaz de romper com o teológico-político (diagnóstico de Nancy) em seu discurso secularizado e secularizador, mas, de modo ainda mais radical, endeusou-se a si mesma, substituindo o Deus único da religião judaicocristã, reinstituindo uma idolátrica Trindade: Razão-Democracia-Mercado - uma trindade em que o Pai sacrifica o Filho no poder do Espírito. A Democracia, filha da Razão, perde sua vitalidade ao ser submetida à força mortal do Mercado. E, assim, 
fundamentalista, alimenta permanentemente a ilusão de liberdade e vitalidade, disfarçando ineficazmente o seu próprio fundamentalismo.

Enquanto um novo discurso salvífico, o único verdadeiro, a democracia se concretiza enquanto uma força totalizadora da vida social, subsumindo a si mesma, ao político (-econômico, devemos acrescentar) todas as dimensões e esferas da existência humana, ao invés de contribuir para sua autonomia emancipada. Ou seja, ao invés de ser efetivamente emancipadora, a democracia, mediante o seu sem-sentido, aprisiona todas as esferas significantes da vida humana, subjugandoas ao seu caráter fundamentalmente dogmático (e aqui destaco o aspecto 'misterioso' do dogma em certas formas do Cristianismo, impossível de ser explicado, mas ainda assim, a ser obrigatoriamente seguido):

As esferas a que me refiro são as da verdade e do significado, aquelas nomeadas mais ou menos corretamente como arte, pensamento, amor, desejo e todos os outros meios possíveis de designar a relação com o infinito - ou, melhor, da relação infinita. Pensar no modo em que estas esferas são heterogêneas à esfera propriamente política é uma necessidade política. Mas o que nos habituamos a chamar de democracia tende, ao contrário, a apresentar essas esferas ou ordens como homogêneas. Ainda que isto permaneça vago e confuso, esta suposta homogeneidade nos desencaminha. (NANCY, 2010, p. 64).

Em uma entrevista datada de 2015, Nancy reafirma este diagnóstico e a importância de pensar o político (e a democracia) fora do jogo do teológicopolítico:

[pensar] em uma política que se colocaria aparte ou se retiraria (tiendrait em retrait) da subsunção e figuração do 'comum'. Isto significa, em primeiro lugar, 'não-totalitária' e 'não-teocrática' (colocado de modo simples), mas também distinta da democracia conforme a praticamos, pois a democracia constantemente confunde a questão - ela permanece alheia, ela não desenha os contornos de um comum completado, mas, ao mesmo tempo, ela distila as características de um 'todo' completo que é inteiramente social (gerenciamento de interesses que, supostamente, são livre e iguais para todos) e assim, faz tanto demais quanto muito pouco para construir um 'sentido' do ser-em-comum. Faz muito pouco porque tudo, ultimamente, tem a ver com 'indivíduos', enquanto faz demais precisamente porque, ao mesmo tempo, é uma associação de indivíduos com o gerenciamento de seus interesses mesclados que representa a (vaga) ideia ou a imagem (borrada) do ser-em-comum'. (NANCY, 2015, p. 105). 
Ainda que Nancy não o diga com todas as letras, ele indica que é a subjugação da ação institucional do Estado aos imperativos do Mercado, o achatamento e anulação de toda e qualquer diferença verdadeira, sob o valor imperialista do dinheiro, que está na base da incapacidade da democracia superar - jogo teológico-político e ir além de seu próprio caráter fundamentalista. O Estado, ao invés de realizar a esfera política, serve à esfera econômica, deixando de fazer política e fazendo mero gerenciamento da vida em comum.

Ao invés de assumir a sua fundamental fragilidade, sua não-autonomia diante do mercado, a democracia permanece teimosamente justificando a si mesma, cujo "resultado foi um tipo de imperativo categórico político e um tipo de intimidação geral do pensamento que provocou tantas possibilidades totalitárias quantas as formas de pensamentos genuinamente hostis ao totalitarismo" (NANCY, 2007, p. 524). Não é esta uma faceta constitutiva do fundamentalismo, célere para criticar todas as falsidades e falácias nos outros, mas incapaz de autocrítica, de autodiscernimento, resultando tanto em teologias autoritárias quanto em formas libertárias de pensamento teológico e ação eclesiástica? Em um registro mais especificamente teológico, não é esta uma das características fundamentais da idolatria, que reduz Deus à crença nele, à figura que dele construímos dogmaticamente?2

Assim como Vattimo, Jean-Luc Nancy também propõe caminhos para a superação e derrota do fundamentalismo, caminhos que não podem passar pela criação de novos fundamentos, de novos pensamentos ou práticas totalizantes, mas pela diversidade plural das fontes de constituição do sentido, liberadas do domínio da política, que se reinventaria no relacionamento igualitário com as demais esferas da existência humana.

\footnotetext{
${ }^{2}$ Não é à toa que a crítica à democracia não possa ser senão uma crítica contra os 'inimigos' da democracia, conforme já constatava Nancy: A democracia tem, assim, sido reavaliada desde a Segunda Guerra Mundial, menos por si mesma, e mais em oposição - e quão veemente e justificada era essa oposição - aos 'totalitarismos', cuja memória (com relação aos fascismos) e cuja crescente condenação (com relação aos stalinismos) constantemente nos convidou a virar as coisas para eles. Mas este dar as costas não nos levou a um reconhecimento do fato de que as catástrofes políticas mais importantes do meio do século não foram o resultado da repentina emergência de inexplicáveis demônios. O esquema explicativo dominante permaneceu o da barbárie, loucura, traição, desvio ou malignidade; usualmente se ignorava, menos deliberada do que sonambulisticamente, Bataille ou Benjamin, Arendt ou ... Tocqueville. Para recolocar em modo esquemático, víamos a democracia sendo atacada, mas não vemos que ela também se expos ao ataque e que ela nos convoca a reinventá-la e não apenas a defende-la. (NANCY, 2008, p. 8)
} 
Nancy, dentre outras formulações, assim apresenta o desafio que se nos apresenta, de pensar a democracia com o político, o político com a democracia: "a política se torna, precisamente, um lugar de detotalização. Ou, poderíamos nos arriscar a dizer: se 'tudo é político' - em um sentido que não seja o teológicopolítico nem o de uma economia política - o é na medida em que o 'tudo' [le tout] não pode ser, nem total, nem totalizado sob qualquer forma. (NANCY, 2010, p. 21, itálicos dele). Trata-se de, efetivamente, romper com o modo teológico-político de pensar, repensando a democracia e a política como esferas parciais da existência humana, não mais como formas totalizantes do pensamento e da ação. $\mathrm{Na}$ linguagem de Habermas, trata-se de pensar a política (e a economia) enquanto forma sistêmica que, ao invés de colonizar o mundo-da-vida, seja dirigida por ele (HABERMAS, 2012, p. 205ss.). Trata-se, portanto, de simplesmente reinventar a nossa forma de civilização, como Nancy se expressou alhures: "não necessitamos de uma revolução política, necessitamos de uma revolução da política, ou em relação a ela. Necessitamos, muito simplesmente (1) de outra 'civilização' que, é claro, significa, acima de tudo o mais, outra forma de reconhecer o sentido" (NANCY, 2015, p. 101).

O que está em jogo, portanto, não é uma reforma ou revolução política, mas uma revolução existencial, civilizacional, na qual a política (e, insisto, a economia especialmente em sua forma capitalista atual) seja subordinada efetivamente às esferas diversas e plurais de produção de sentido que existem exclusivamente fora do político e, assim, fora da dominação do Estado, do Mercado, da Ciência e da Mídia. Trata-se da revolução ontológica do ser-em-comum, a única revolução que efetivamente seria capaz de romper com o teológico-político:

A política não é responsável pela identidade e destino do comum, mas apenas pela regulação - ainda que infinita - da justiça. (Tem, assim, a ver com poder.) O comum, porém, é que coloca a existência em funcionamento. (Tem, então, a ver com sentido). O que está em jogo aqui é a separação entre sentido e poder. Um certamente não exclui o outro, mas um não pode, de outro lado, substituir o outro. (isto não enfraquece a legitimidade da revolta, mas, sim, revela seu horizonte último.) $\mathrm{O}$ teológico-político subsume poder e sentido, justiça e existência; ele absorve o comum no político (ou vice-versa). Enfim, não mais se sabe o que significam 'comum' ou 'político'. (NANCY, 2010, p. 41). 
A tarefa do pensamento, a tarefa propriamente política do pensamento, seria a renovação do assombro, da perplexidade que anima a busca do sentido, de um novo olhar para a democracia:

\begin{abstract}
E é isto o que tanto nos torna perplexos em relação à democracia. Trata-se de pensar o intervalo entre o comum e o político: não pertencemos a um do mesmo modo que pertencemos ao outro, e 'tudo' não é 'político'. E, do mesmo modo, 'tudo' não é comum, visto que o 'comum' não é nem uma coisa, nem todas as coisas, isto é, um todo [un tout]. Entre poder e sentido há proximidade e distanciamento, ao mesmo-tempo-juntamente-uma relação de poder e uma relação de sentido ... É, talvez, uma forma completamente nova do relacionamento do ser humano consigo mesmo, no qual o ser humano não é mais 'seu próprio fim' (se tal é, de fato, a base da democracia), a menos que sejamos capazes de nos distanciarmos de nós mesmos a fim de irmos além. (NANCY, 2010, p. 41).
\end{abstract}

Se pudemos dizer que a democracia se constituiu idolatricamente, substituindo Deus por si mesma e ocultando seu caráter idolátrico mediante a afirmação da autonomia humana, a superação do teológico-político precisa passar necessariamente pelo teológico, mas por um fazer teológico efetivamente emancipatório, capaz de, ao mesmo tempo, denunciar o discurso da autonomia humana em relação a Deus como um discurso totalitário e anunciar a promessa de uma autonomia não mais anti-heteronômica, mas de uma autonomia intersubjetiva, interdependente, que reconhece Deus não mais como o todopoderoso, mas como o todo amoroso, não mais como a Unidade fechada em Simesmo, mas como a Trindade intersubjetivamente aberta a toda a sua criação.

É claro, esta descrição não é nancyana, ainda que, suponho, seja fiel às possibilidades abertas por seu pensamento. A descrição de Nancy proporia um novo 'ateísmo' - mas não seria esse novo 'ateísmo', de fato, outra forma de dizer uma 'nova teologia', não mais constituída sob o signo da ontoteologia?

Por um lado, a sombra do teológico-político é imensa, recaindo sobre a totalidade de nossa cultura, e, mais do que nunca, em sua versão secularizada e imanentizada (a versão representada em parte por Rousseau - mas somente em parte, visto que Rousseau também declarou que a pura democracia só seria boa para 'um povo de deuses'. Por outro lado, não temos ideia do que 'democracia' e 'política' possa significar a partir do momento em que forem removidas da ordem ou configuração metafísica. É por isso que estamos tão perdidos ou perplexos. Pela mesma razão, sequer sabemos ainda o que a 'secularização' é ou pode ou deveria ser (seria ela a mera transposição do 'teológico' em termos profanos, ou a 
abertura de um espaço totalmente outro?). Ainda não temos desenvolvido um ateísmo - e esta é a verdade do que tem sido chamado de a 'crise' do 'político'. (NANCY, 2007, p. 524).

\section{Conclusão}

Deve ter ficado claro, ao longo da exposição do pensamento de Vattimo e Nancy, que não é possível pensar o fundamentalismo apenas enquanto uma identidade religiosa, enquanto um modo arcaico, pré-moderno de ver o mundo. Ambos conferem validade a uma forma de ver o fundamentalismo como um modo moderno de conceber a realidade e de agir nela, conforme expresso, por exemplo, da seguinte maneira:

percebo o fundamentalismo como uma estética do existir, e não como uma identidade especificamente religiosa. Nesse sentido, percebo 0 fundamentalismo não como "revolta contra a modernidade", mas como o alter ego reprimido da modernidade, a barbárie que se encobre nos monumentos da civilização. Em outras palavras, a atitude fundamentalista é o grotesco da experiência moderna da verdade, uma estética vivenciada pelo avesso, sob o signo da perversão. Estética vivenciada não só por fundamentalistas religiosos, mas especialmente por fundacionalistas de toda estirpe. Enquanto uma estética do existir, o fundamentalismo está em/entre nós; a cada instante sua sombra se projeta sobre nossas práticas e revela a pouca luz que o esclarecimento moderno nos trouxe. (ZABATIERO, 2008, p. 18).

Não é possível superar o fundamentalismo sem o reconhecimento de que ele não é um agente 'externo' à razão, mas, ao contrário, é um elemento constitutivo da própria racionalidade humana conforme concebida também pela modernidade. Assim como não se pode melhorar a democracia sem uma autocrítica consciente e consistente, como evocam Nancy e Vattimo, também não é possível superar o fundamentalismo enquanto não se reconhecer que ele não é meramente um modo religioso de pensar. Se há algo evidentemente em comum nos pensamentos de Vattimo e Nancy, conforme o breve recorte aqui apresentado, é o reconhecimento de que a crise em que vivemos não pode ser compreendida apenas como crise política, mas como crise ontológica e epistemológica. 
Ao reconhecer o perigo que os fundamentalismos religiosos impõem à democracia somos convocados também a reconhecer o perigo insidioso do fundamentalismo enquanto modo de pensar e praticar a democracia em nosso tempo. A democracia, uma promessa segundo Jacques Derrida, não poderá se 'cumprir' enquanto seu caráter escatológico-apocalíptico não for reconhecido. A democracia não é a melhor forma possível de governo. A democracia não é a única forma legítima de governo. A democracia é um dom, uma tarefa, um desafio e uma tentação ${ }^{3}$ Esperamos ter mostrado, na interpretação dos filósofos europeus, estas características da democracia e do político, tendo destacado, em especial, a tentação democrática - a de se pensar como a única forma legítima de organização política da vida humana. A tarefa, ainda segundo nossos interlocutores, então, é vencer a tentação, pensando a democracia e a política de modo radicalmente novo, fraco e 'comunista'.

\section{REFERÊNCIAS}

BADIOU, Alain. São Paulo: a fundação do universalismo. São Paulo: Boitempo, 2009.

BRUEGGEMANN, Walter. The land: place as gift, promise, and challenge in biblical faith. Minneapolis: Augsburg Fortress, 2003.

HABERMAS, Jürgen. Teoria do agir comunicativo: sobre a crítica da razão funcionalista. São Paulo: Editora WMF Martins Fontes, 2012. v. 2.

MENDÉZ, German Labrador. La democracia emplazada: memoria de las plazas, historia popular y crítica poética después del 15M. In: SERRANO, Eunate et al. (ed.). 15MP2P: Una mirada transdisciplinar del 15M. s/l., p. 170-192, 2014. Disponível em: https://tecnopolitica.net/sites/default/files/15MP2P_Mayo2014.pdf. Acesso em: 1 jun. 2020.

NANCY, Jean-Luc. Finite and infinity democracy. In: AGAMBEN, Giorgio et al. Democracy in what state? New York: Columbia University Press, 2011.

NANCY, Jean-Luc. Nothing but the world: an interview with Vacarme. Rethinking Marxism: a journal of economics, culture \& society, v. 19, n. 4, p. 521-535, 2007.

${ }^{3}$ Evocando o título de um livro de Walter Brueggemann (2003). 
NANCY, Jean-Luc. Política e/ou política. Alea, Rio de Janeiro, v. 17, n. 1, p. 166-178, 2015.

NANCY, Jean-Luc. Politics and beyond: an interview with Jean-Luc Nancy. Diacritics, Ithaca, v. 43, n. 4, p. 90-108, 2015.

NANCY, Jean-Luc. The truth of democracy. New York: Fordham University Press, 2010.

VATTIMO, Gianni. Adeus à verdade. Petrópolis: Vozes, 2016.

VATTIMO, Gianni. Democracy and hermeneutics. Telos, Candor, n. 161, p. 9-15, 2012.

VATTIMO, Gianni. Depois da cristandade: por um cristianismo não religioso. Rio de Janeiro: Record, 2004.

VATTIMO, Gianni. Hermeneutics and democracy. Philosophy \& Social Criticism, California, v. 23, n. 4, p. 1-7, 1997.

VATTIMO, Gianni. Não ser Deus: uma autobiografia a quatro mãos. Petrópolis: Vozes, 2018.

VATTIMO, Gianni; ZABALA, Santiago. Comunismo hermenéutico: de Heidegger a Marx. Barcelona: Herder, 2012. 